\title{
Prediking oor politieke sake - riglyne vanuit Romeine 12-15
}

\author{
C.J.H. Venter \\ Departement Diakoniologie \& Missiologie \\ Potchefstroomse Universiteit vir $\mathrm{CHO}$ \\ POTCHEFSTROOM
}

\begin{abstract}
Preaching on political issues - guidelines from Romans 12-15

Preaching on political issues is a very topical matter, especially in the currem situation in South Africa. This matter is extensively dealt with in literature in the field of the Old and New Testament, Homiletics and Ethics. The aim with this article is to explore the Pauline paranesis in Romans 12-15 to discern concrete guidelines on handling political issues in preaching. As point of departure the expression God's mercy (Romans 12:1) is investigated closely, as the concept of God's mercy is the foumdation stone of the total paranesis in Romans 12-15. Regarding preaching on political issues, the fact that the new aeon has already come and will finally come, leads to certain conclusions. The responsibility of the congregation to test and approve what God's will is - also in political matters - is stressed. The kingdom of God as the predominant kingdom, relativises earthly (political) kingdoms. The responsibility to equip the congregation to discern political issues in the light of Scripture is dealt with in this regard. Finally, perspectives are given on the relation between state and believer. In conclusion the command to Christians to love each other as believers, to live in peace with everyone and to love enemies is also highlighted.
\end{abstract}

\section{Terminologie}

In hierdie artikel word om 'n spesifieke rede nie van politieke prediking gepraat nie, maar van prediking oor politieke sake. Politieke prediking kan per definisie eensydig vertolk word (Müller, 1985:148; 1992:27-41). Net so min as wat van byvoorbeeld ekonomiese prediking of seksuele prediking gepraat behoort te word, behoort van politieke prediking gepraat te word. Die belangrikste argument vir die keuse van 'n ander term as politieke prediking is egter dat dié term die indruk mag skep dat ' $n$ hermeneutiese sleutel van buite die Skrif (i.c. politiek) gekies word om die Skrif te verklaar. Veral om hierdie rede word gekies vir die omskrywing prediking oor politieke sake. Hiermee word dan by implikasie gestel dat prediking van die Woord strek oor alle lewensterreine - ook die politiek, maar dan vanuit die Woord as beginpunt. Dit gaan om die Woord in die werklikheid van die politiek. 
Met politiek word in hierdie artikel bedoel die georganiseerde ruimte (Snyman, 1994:150) waarbinne burgers se lewe en lewenskwaliteit georganiseerd gestruktureer word deur die mag van die staat.

\section{Aktualiteit van die onderwerp}

Sonder teëspraak kan gesê word dat 'n kernmoment in homiletiese en etiese besinning vandag wentel om prediking wat politieke sake toepaslik belig (Pieterse \& Theron, 1994:141-154; Venter, 1991:213-324). Nie net op die SuidAfrikaanse toneel word homileties oor dié saak besin nie maar ook in die buiteland (Velema, 1972:31-155; Oosterhof, 1987:142 e.v.; Josuttis, 1980:40 e.v.). 'n Homileet soos Long (1989:83 e.v.) motiveer ook prediking oor politieke en ander sake vanuit die dimensie van die aardse werklikheid waarbinne lidmate lewe. Dit moet ook hier gestel word dat prediking oor politieke sake 'n kemdimensie is in die sogenaamde bevrydingsteologie sedert die sewentigerjare (vgl. De Gruchy, 1970:8-15 en vir kommentaar Floor, 1974:8).

Müller (1992:27-41) bepleit in die lig van die oorgangsfase in Suid-Afrika 'n hermeneutiek op die intervlak tussen eksegese en sosiale analise. Hy gebruik meermale die uitdrukking hermeneutiek van die markplein. Hiermee het Müller prediking oor politieke sake binne die besinningsveld van die hermeneutiek geplaas. As juis in die proses van hermeneuse die Woord van God en die werklikheid van vandag, ook die politieke werklikheid, mekaar dan ontmoet in 'n proses van hermeneutiese wisselwerking, dan behoort opnuut na die politieke dimensie gekyk te word om die Woord tyd- en situasiegerig te kan bedien. In hierdie hele proses moet die primaat van die Woord vooropgestel word.

Juis om hierdie rede word vir dié artikel ten doel gestel om riglyne vir prediking oor politieke sake te bied vanuit Romeine 12:15:13 as primêre bron. Riglyne vir prediking oor die politiek is reeds meermale gebied vanuit die Ou Testament (vgl. Snyman, 1992:150-156; Van Rooy, 1991:31-42; Helberg, 1991:1-15). Ook vanuit die vakgebied van die Etiek is reeds meermale besin oor die hantering van politieke sake in die prediking (Van Wyk, 1991:172-192; 1992:551-562; Vorster, 1985:100-118). Vanuit 'n breër perspektief op die Nuwe Testament is oor dié vraagstukke ook nader besin (Floor, 1985:94-99). Meermale is Romeine 13 betrek in besinning oor die staat en die gesag van die staat (Abineno, 1972:2327; Goldstein, 1973:88-104; Hutchinson, 1971:49-59).

Die omvangryke Pauliniese paranese in Romeine 12:15-13 is egter nog nie genoegsaam ontgin vir riglyne met die oog op prediking oor politieke sake nie. Juis hierom sal dié gedeelte uit Romeine verken word, met as navorsingshipotese dat Romeine 12-15 gegewens bevat wat ondersoek behoort te word met as verwagte resultaat 'n nadere fundering van (etiese) riglyne vir prediking oor politieke sake. 


\section{Verkenning uit 'n seleksie van resente literatuur met die oog op riglyne vir prediking oor politieke sake}

\section{- S.D. Snyman (1992)}

Snyman (1992:152-153) stel die volgende riglyne vir prediking oor politieke sake: dié prediking moet bediening van die Woord wees en bly; lidmate moet deur prediking oor politieke sake toegerus word vir hulle taak om as Christene hulle geloof uit te leef deur byvoorbeeld kritiese vrae te stel oor politieke aksente van die eie en ander politieke partye. Politiek wat in die prediking ter sprake kom, moet nie die geloofwaardigheid van die kerk in gedrang bring nie. Snyman stel ook dat die predikant self hom nie sodanig aan 'n politieke party behoort te verbind dat hy nie meer ' $n$ kritiese afstand kan handhaaf nie. Hier moet gestel word dat Snyman se artikel verryk sou kon word met die omvattende koninkryksperspektief op politieke sake.

In sy afwysing van slegs a-politiese prediking (dus prediking wat net en alleen handel oor die persoonlike geloofslewe) sowel as prediking vanuit 'n politieke hermeneutiek, bepleit Müller (1985:143-146) koninkryksprediking, prinsipieel en intensioneel:

Prinsipieel omdat die koninkryk die domein van God se heil, sy regering en sy heil op aarde verteenwoordig. En intensioneel omdat die boodskap van die koninkryk van God se evangelie - en daarom as God se alternatief - vir die wêreld in alle neerdrukkende situasies aangebied moet word (Müller, 1985:147).

Koninkryksprediking waarin ook politieke sake belig word, sluit dan die volgende in: eskatologiese prediking, prediking oor die deurbraak van die koninkryk, provokatiewe en konfrontatiewe prediking en prediking met 'n openbare en verborge werking (Müller, 1985:146-150).

Die sterk aksent op koninkryksprediking moet in Müller se uiteensetting gewaardeer word. 'n Nadere uiteensetting van die gawes van die koninkryk (geregtigheid, liefde, vrede) sou egter die waarde van die artikel verhoog het.

\section{- J.H. van Wyk (1985)}

Van Wyk (1985:50-57) beskou die volgende komponente as boustene in die etiek van die politiek: liefde, geregtigheid, selfverloëning, versoening, eenheid, bekering en waarheid. Deurgaans moet met die deurwerkende krag van die sonde in die politiek rekening gehou word. In 'n latere publikasie (1992:557558) bepleit van Wyk 'n koninkryksentriese benadering téénoor 'n piëtistiese, kwiëtistiese of politistiese benadering tot politieke sake in die prediking. Hy motiveer sy keuse deur te stel dat 'n koninkryksentriese benadering alle aardse 
koninkryke relativeer (betreklik maak) en relateer (dit wil sê in verhouding tot die koninkryk bring).

\section{- W.H. Velema (1972)}

Velema (1972:37) stel dat in prediking oor politieke sake ons die heerskappy van Jesus Christus as oorkoepelende dimensie moet sien. Binne die heerskappy van Christus moet eerstens die doen van geregtigheid ter sprake gebring word: "Vanuit het recht dat God op ons heeft, kunnen we gerechtigheid omschrijven als datgene wat recht is voor God en de mensen" (Velema, 1972:37). Saam met geregtigheid moet die liefdesgebod ter sprake gebring word - die gebod "... dat de verzakeliking binnen de structuren doorbreekt en tot een ik-gij verhouding binnen de struckturen oproept" (Velema, 1972:37). Laastens moet die dimensie van ordening (dit wil sê dat God duidelik gestelde lewensverbande gewil het wat aan bepaalde reëls onderworpe is) in prediking oor politieke sake in berekening gebring word (Velema, 1972:37).

$\mathrm{Na}$ hierdie verkenning van enkele meer resente bydraes vir riglyne in prediking oor politieke sake, is dit duidelik dat daar tussen die aangehaalde outeurs 'n bepaalde refrein is wat telkens terugkeer as riglyne vir prediking oor politieke sake, naamlik die allesoorheersende betekenis van die koninkryk van God, versoening, geregtigheid, liefde en die (staats-)ordening wat deur God ingestel is. Hierby word 'n kritiese ingesteldheid vanuit die Woord van God in besonder by predikante en lidmate ten opsigte van die politiek bepleit.

\section{Perspektiewe vanuit Romeine 12-15}

Die doel met hierdie onderdeel van die artikel is om Romeine 12-15 te verken vir moontlike perspektiewe op prediking oor politieke sake; om in die lig van die bevindinge sekere perspektiewe uit die verkende literatuur nader te fundeer en om die aandag te vestig op verdere perspektiewe wat uit Romeine 12-15 na vore mag kom.

\subsection{Motivering vir die keuse van Romeine 12-15 as ondersoekmateriaal}

'n Eerste motivering vir die keuse van die betrokke hoofstukke uit Romeine hou verband met die bree struktuur van die Romeinebrief. Meer outeurs aanvaar dat ons in die Romeinebrief basies te doen het met die struktuur van 'n hofsaak: aanklag, uitspraak, vonnis (Coetzee, 1995:49-51; Nygren, 1978:38-41; Käsemann, 1980:ix-xi). Romeine 12 volg dan na die uitspraak (vryspraak) op grond van God se toegerekende geregtigheid. Met Romeine 12 begin die vyfde hoofdeel met as sentrale tema die lewenswandel van die geregverdigde: 'n lewende dankoffer (Coetzee, 1995:5). Romeine 12-15, as omvattende paranese gestruktureer, handel dus inderdaad oor die lewenspraktyk van die geregverdigde 
(vrygespreekte) gelowige. Hierdie lewenspraktyk is so wyd dat minstens gestel kan word dat politieke sake hiervan nie uitgesluit mag word nie.

'n Verdere motivering vir die keuse van hierdie hoofstukke is dat 'n kursoriese verkenning van die inhoud en interne struktuur van Romeine 12:1-15:13 aan die lig bring dat bepaalde temas in hierdie hoofstukke ineengevleg is, temas wat direk verband hou met prediking oor politieke sake. Temas soos versoening (12:1); toewyding aan God (12:1), 'n kritiese beoordeling van die huidige aeon (12:2), die kerk en toerusting van gelowiges (12:6-8); 'n liefdestema (12:19-23), die optrede van 'n burger teenoor die staat (13:1 e.v.), selfverloëning (15:1-6) en 'n koninkrykstema is almal aspekte wat roep om nadere besinning.

Uiteraard kan alle voorkomende temas in Romeine 12-15 nie behandel en verken word nie. Die omvang van 'n artikel soos hierdie dwing 'n outeur om 'n seleksie van temas aan te stip en nader te bekyk.

\subsection{Die perspektief van versoening en prediking oor politieke sake}

Wanneer die tema van versoening in prediking oor politieke sake behandel word, word 2 Korintiërs 5:18-21 meermale aan die orde gestel, juis omdat die tema van versoening en die bediening van die versoening so heg verbind word (as dubbele parallelisme) in hierdie gedeelte (Venter, 1991:215-216). Die begrip wat in 2 Korintiërs 5:18-21 vir versoening gebruik word (katallage) het hier duidelik die nuanse van omruiling. In vers 21 word eksplisiet gestel dat God Christus in ons plek as sondaar behandel het sodat ons deur God vrygespreek kan word.

Die vraag is nou of daar direk sprake is van versoening in Romeine 12. Dié vraag moet bevestigend beantwoord word. Weliswaar word die begrip katallage nie in Romeine 12:1 gebruik nie, maar wel die begrip oiktirmos. Dat die ontferming van God 'n grondliggende plek inneem as vertrekpunt vir die totale paranese in Romeine 12-15 word erken (Venter, 1985:47). Die begrip oiktirmos het die nuanse van ontroering wat gewek word deur die ellende van 'n mens in nood (Rienecker, 1980:II 29). Dié begrip word dikwels omruilbaar gebruik met eleos. In die LXX byvoorbeeld, word die begrip eleos omruilbaar met oiktirmos gebruik in die sin van 'n meerdere wat neerbuig na 'n mindere. In hierdie nuansering kan die begrip eleos-oiktirmos dus beskou word as breë ekwivalant van die Hebreeuse begrip chesed.

Wat opvallınd is, is dat Paulus die begrip eleos-oiktirmos in besonder in Púmeine 9-12 gebruik. Dit is juis die omvattendgerigte ontferming van God in Romeine 9-11 wat uitloop op die lofsang in Romeine 11:33-36, oorloop in Romeine 12:1 as begronding vir die paranese en dan deurloop na Romeine 15:9 as afsluiting van die paranese in die lofsang dat ook die nasies God vir sy onferming sal prys. Die feit dat die sentrale indikatief van God se ontferming 
vooropstaan en funderend is - nie net vir die lewenswandel van die gelowige nie, maar ook vir dié van die predikant en vir pastorale vermaning tot die regte lewenswandel - is veelseggend. Die vasstelling sê konkreet dat ons met ons optrede - ook teenoor mekaar - nie met haat moet begin nie, maar by God se ontferming. Hy wat self ontferming ontvang het, moet onferming deurgee - ook op politieke vlak!

Die aandag word in hierdie verband ook gevestig op die volgorde: indikatiefimperatief in Romeine 12:1. Die imperatief word gefundeer in die indikatief. God se ontferming noop ons om onsself as lewende dankoffer ter beskikking van God te stel. Eers volg die indikatief en dan daarop gefundeerd die imperatief. Dit is juis 'n kenmerk van strominge in die politieke teologie dat hulle stel dat die indikatief eers realiseer as die imperatief nagekom word. Die praxis van bevryding is bepalend vir die indikatief van ontferming. Deur menslike aksie primêr te plaas moet sekondêr by genade, versoening en ontferming uitgekom word.

Dit moet net kortliks genoem word dat die orde indikatief-imperatief ook bepalend is vir die wyse van onderrig van die Tien Gebooie in die kategese en ook vir vermaning in die herderlike bediening. Wie in hierdie werk die verhouding indikatief en imperatief skeeftrek, beland of in moralisering of in 'n vorm van fatalisme (vgl. Coetzee, 1996:8-10).

\subsection{Die perspektief van die twee aeone en prediking oor politieke sake}

Op grond van God se ontferminge in Romeine 12:1 volg die vermaning in vers 2: "En word nie aan hierdie sondige wêreld gelykvormig nie". Die negatiewe bevel volg na die voorafgaande positiewe bevel: "Stel julleself as lewende dankoffers tot beskikking van God". Dit kan gesê word dat die inhoud van die bevel om onsself as lewende dankoffers aan God te wy, juis inhou om nie aan hierdie sondige bedeling gelykvorming te word nie. Die gelowige moet 'n "kritische Distanz" (Schlier, 1977:363) teenoor die huidige aeon bewaar. Wat by die behandeling van die begrip aeon in gedagte gehou moet word, is dat dit hier gaan om die dubbele dimensie van tyd in die Nuwe Testament (vgl. De Vuyst, 1979:87). Die nuwe bedeling het reeds aangebreek, maar moet ook nog voltooi word. Met hierdie aeon fokus Paulus veral op wat tans nog ontbreek. Hierdie is nog die bedeling van onvoltooidheid, van sonde wat in beginsel oorwin is maar wat tog nog 'n sekere greep op die gelowige het. Hierdie bedeling het nog 'n eie styl van optrede en 'n eie aard van lewe. Juis daarom is hierdie bedeling nog die bedeling van sonde, ook politieke sonde - en die bedeling van vermaning om teen die sonde te stry.

In prediking oor politieke sake is dit nodig om die tweefasekoms van die aeon in berekening te bring. Ons bedryf politiek - en preek oor politieke sake - in 'n 
onvoltooide aeon met nog veel gebrokenheid. Die finale koms van die koninkryk kan nie met politieke programme (of verskille!) verwesenlik word nie; God self laat dit aanbreek. Ons mag nou wys op die reeds en die nog nie van hierdie koms.

Die nog nie van die huidige bedeling beteken konkreet dat die sondige in die politiek nie met 'n enkele preek of 'n paar preke opgelos kan word nie. Daarvoor is die gebrokenheid te diep. Preek dus oor politieke sake om weer en weer (ook na 'n verkiesing!) te kan preek.

Andersyds hou die reeds van die huidige bedeling ook in dat 'n kritiese afstand bewaar moet word. Die bedienaar moet sy kritiese funksie ten opsigte van politieke sake behou. Alleen so sal hy byvoorbeeld teen korrupsie in politieke party $A$, onreg in party $B$ en arrogansie in party $C$ kan preek terwyl hyself vanuit die reeds van die gekome koninkryk hom nie kompromitteer ten opsigte van een party nie.

\subsection{Die perspektief op die wil van God en die prediking oor politieke sake}

Drietalle is opvallend in Romeine 12:1-2 (Venter, 1985:27). Van die offer word byvoorbeeld gestel dat dit lewend, heilig en aan God welgevallig moet wees. Van die wil van God (12:2b) word gestel dat dit goed, welgevallig en volmaak is. Nou is dit juis die wil van God wat onderskei moet word. Dieselfde begrip wat hier vir onderskei gebruik word, word ook in Romeine 2:18 gebruik in verband met die onderskei van wesenlik dinge. In Romeine 2:18 word onderskei gebruik in die konteks van die ou bedeling: van aanklag, vonnis, straf en dood en die verkeerde toepassing van die wet. Hierdie onderskeid behoort nog tot die bedeling voordat die gelowige met Christus gesterf het en opgewek is (Romeine 6). Hierteenoor staan die daad van ware onderskeiding van die wil van God in die nuwe aeon en met denke wat venuwe is. Dit is juis nuwe (eskatologiese) denke wat gerig is op die onderskeiding van die wil van God in verskillende situasies, ook politieke situasies.

Hierdie gegewens laat besondere lig val op prediking oor politieke sake. Daar is byvoorbeeld dikwels in die verlede deur sowel die voor- as teenstanders van apartheid ' $n$ beroep op die Bybel gedoen vir die regverdiging van hulle standpunte. Die tyd en ook die afloop van apartheid het die onmoontlike in so 'n siening aan die lig laat kom. God se wil is nie vir alle mense en te alle tye altyd een en dieselfde nie. Juis daarom moet sy wil in elke situasie deur nuwe denke biddend onderskei word, gesoek word - en dan gehoorsaam word.

'n Volgende aspek wat hier na vore kom, raak die prediker oor politieke sake. 
Die prediker is die bedienaar van God in die gemeente. Hy is nie die gewete van die gemeente nie. Hy moet lidmate toerus, hulle gewete opskerp om die wil van God te onderskei en nie sy eie wil aan hulle as die wil van God oplê nie. Die gemeente kom om in die prediking oor politieke sake 'n perspektief te vind op die wil van God - nie op die dominee se politieke program of voorkeure nie (vgl. Velema, 1972:20 e.v.).

\section{5 'n Perspektief op die koninkryk van God en prediking oor politieke sake}

In die paranese in Romeine 12-15 kom die uitdrukking koninkryk van God voor in Romeine 14:17: "Die koninkryk van God is nie 'n saak van eet en drink nie, maar van gehoorsaamheid aan God, vrede en vreugde wat die Heilige Gees gee."

Die mees direkte aanleiding vir dié uitdrukking in verband met die koninkryk van God lê in Romeine 14:16a: "Die goeie in die gemeente moet nie deur buitestanders belaster word deurdat ' $n$ medebroeder in die gemeente deur voedsel te gronde gerig word nie - juis omdat die koninkryk van God nie in die eet of nie eet van sekere voedsel bestaan nie."

Die begrip koninkryk van God word veral op drie betekenisvlakke in die Nuwe Testament gebruik, naamlik as gebied, as regering en as aanduiding van dit wat met die onderdane in sy ryk gebeur (vgl. Bauer, 1979:134-135). Juis in die Evangelies word daarop klem gelê dat die koninkryk van God gekom het in 'n Persoon. Dit is daarom opvallend dat die koninkryksbegrip in die Briewe van Paulus konsekwent verbind word met God (1 Korintiërs 4:20; Efesiërs 5:5).

In Romeine word die begrip koninkryk alleenlik in 14:17 gebruik. Van belang is dat die begrip in wyer konteks verbind word (Venter, 1985:169). Eerstens is daar 'n verbinding met die "goeie," dit wil sê met God se heilswil. Van God se heilswil word die oorgang nou gemaak na God se koninkryk. Vervolgens word koninkryk in 14:17 ook met 15 b verbind: Christus het gesterf - juis daarom moet 'n medegelowige nie deur voedsel te gronde gerig word nie, want Christus se sterwe is meer as voedsel. Koninkryk word voorts ook in vers 17 verbind met die Heilige Gees as bewerker van die konkrete werklikheid van die koninkryk in geregtigheid, vrede en blydskap. Die uiteensetting toon dus dat die koninkryk van God in Romeine 14:17 'n trinitariese karakter het.

Die koninkryk van God relativeer alle politieke aardse koninkryke en die gawes van die koninkryk transendeer die gawes en die gebruik van die gawes (i.c. eet en drink) van aardse koninkryke.

Wat is die gawes van die koninkryk? Kruger (1983:87-89) stel dat geregtigheid 
'n gawe (verbondsgawe) van God aan die sondaarmens is - juis teenoor eiegeregtigheid en geregtigheid deur wetsvolbrenging (Porter, 1996:14). In die konteks van Romeine 14:17 is die vermaning juis om mekaar nie deur voedsel ten gronde te rig nie - want sowel sterkes as swakkes deel in God se geregtigheid!

'n Volgende koninkryksgawe in Romeine 14:17 is vrede, hier veral bedoel as vrede binne die gemeente, vrede wat die klimaat skep om mekaar op te bou. Juis in Romeine 14:15 staan vrede teenoor verlore laat gaan en ook teenoor afbreek (vers 20). 'n Klimaat vir vernieting en afbreek van mekaar word geskep as voedsel byvoorbeeld gebruik word sonder om mekaar in ag te neem, en as gelowiges mekaar daarin veroordeel. Die teenoorgestelde van veroordeling is vrede, nie alleen as gawe van die Gees nie, maar ook as "Wirklichkeit des Endheils" (Wilckens, 1982:III:94).

'n Laaste gawe van die Gees wat in vers 17 genoem word, is vreugde. Paulus se uitspraak in 1 Korintiërs 2:3 verhelder die begrip vreugde (chara) in Romeine 14:17. Hy skryf dat hy nie na Korinte wou kom om mense wat hom vreugde besorg het, hartseer (lupe) te maak nie. Ook in Romeine 14:17 funksioneer chara as teenoorgestelde van lupeitai. Dus: deur die gebruik of nie-gebruik van kos kan 'n medebroeder hartseer of verbitterd gemaak word. So 'n optrede is strydig met die liefde as eerste vrug van die Gees. Dit is egter ook strydig met 'n volgende aspek van die vrug van die Gees, naamlik om 'n medebroeder vreugde te besorg.

Hierdie uiteensetting bring veral die dimensies van selfverloëning en selfbeheersing in politieke sake en in die prediking oor politieke sake na vore.

\section{6 'n Perspektief op toerusting van die gemeente en prediking oor politieke sake}

Gewoonlik word Efesiërs 4 betrek wanneer ondersoek ingestel word na die toerusting van die gemeente vir hulle dienswerk in die wêreld. Tog kom die saak van toerusting, meer spesifiek die organe vir die toerusting van gemeente, duidelik ter sprake in Romeine 12:1-8. Die gedagte van kerkwees word prominent verwoord in Romeine 12:4 in die metafoor van die liggaam en die ledemate. Wat egter in besonder na vore kom in verse 6-8 is nie net dat God gawes gee om sy kerk toe te rus nie, maar ook dat hy 'n volheid gawes hiervoor gee (Venter, 1996:36). Die feit dat God 'n volheid gawes gee, kom na vore in die struktuurpatroon van Romeine 12:6-8. Hierdie stelling word toegelig deur nou die verse te herskryf om die struktuurpatroon uit te lig en te beklemtoon (Venter, 1996:36-37). 
Vers 6: $A s$ dit die gawe is om God se boodskap te verkondig, laat ons dit gebruik ...

Vers 7: As dit is om te dien, laat ons dien. As dit is om onderrig te gee, laat ons onderrig gee

Vers 8: As dit is om mense te bemoedig, laat ons hulle bemoedig.

As ons gee, laat dit sonder bybedoelings wees As ons leiding gee, dan (= laat dit wees) met toewyding. As ons ander help, dan (= laat dit wees) met blymoedigheid.

Ons het hier met 'n $4+3=(7)$-herhalingspatroon te doen in die gebruik van as (ons) en laat of laat dit dan (Venter, 1985:46-47). En let wel hierdie herhalingspatroon $(4+3)$ impliseer ook die getal van volheid. Paulus gebruik meermale 'n soortgelyke struktuurpatroon om volheid en afgerondheid uit te druk, byvoorbeeld ook in 1 Korintiërs 4:9-13. Dus: God gee voluit 'n volheid van gawes en dienste wat voluit beoefen moet word juis om gelowiges toe te rus (vgl. ook Kăsemann, 1980:333-334).

Die gawes wat hier genoem word, is so wyd soos die lewe van die gemeente self. Veral die gawe om leiding te gee in die kerk (prohistamenos) sou ook die aspek van toerusting omvat om politieke sake en partye in die lig van die Woord te beoordeel - bowenal om leiding te gee om die wil van God in 'n bepaalde politieke situasie vas te stel.

\section{7 'n Perspektief op die gesag van die staat en prediking oor politieke sake}

'n Nadere ontleding van Romeine 13:1-7, die locus classicus oor die plek en gesag van die staat, is hier gewens (vgl. Venter, 1996:81).

'n Verkenning van die struktuur van hierdie bepaalde perikoop toon duidelik dat sekere struktuurmerkers wat gesag uitdruk, prominent voorkom in Romeine 13:14. Die begrip eksousia (gesag) kom voor in verse 1,2 en 3, en die begrip owerhede (argontes) ook in vers 3. Hiermee saam word die voorsetsel hupo (onder) nie minder nie as drie keer in vers 1 saam met die werkwoord tasso (vers 1, 2 en 5) gebruik. Die voorsetsel huper (bo-oor) as aanduiding van die gesag van die owerheid word ook in vers 1 gebruik. Wat op grond van hierdie uitdrukkingswyse duidelik is, is dat die gedagte van orde en gesag hier op die 
voorgrond staan. In die verhouding van die owerheid tot mense, staan gesag voorop.

Hierdie gesagsdimensie in Romeine 13:1-7 word egter van vers 6 af omgekeer. In hierdie gedeelte is 'n duidelike verandering in die gedagtegang en struktuur sigbaar. Die begrip eksousia (gesag) staan nie meer in verse 4 tot 6 op die voorgrond nie. Die begrippe theou diakonos (vers 4) en leitourgoi theou vorm 'n nuwe, feitlik beklemtoonde lyn in die gedagtegang. Die uitdrukking diakonos en leitourgoi vorm boonop 'n omramingspatroon vanaf vers 4 tot 6 en beklemtoon sodoende dat alles wat in hierdie verse staan, besien moet word vanuit die perspektief dat die owerheid God se dienaar (diakonos/leitourgos) is (Venter, 1985:92).

In sy verhouding tot God is die owerheid dus 'n dienaar. Hierdie uitspraak van Paulus moet as besonder veelseggend beskou word teen die agtergrond van die destydse beskouing van die staat. Die keiser as hoof van die staat het homself as god beskou. Van hierdie keiser stel Paulus dat hy 'n dienskneg van God is, nie God self nie.

Die bevinding uit die ontleding van hierdie gedeelte is dat die staat in sy verhouding tot onderdane in 'n posisie van gesag staan, maar teenoor God staan die owerheid in die verhouding van 'n dienaar.

\subsection{Die liefdesmotief en prediking oor politieke sake}

Vroeër in hierdie artikel is dit reeds gestel dat die dimensie van naasteliefde 'n herhaalde refrein is in literatuur waarin gehandel word oor prediking wat die terrein van die politiek as toepassingsveld het.

Die aspek van naasteliefde word op 'n besonder genuanseerde wyse nader uitgewerk in Romeine 12:9-21.

Op grond van die groot ontferming van God (vers 1) volg as eerste opdrag onder die riglyne vir die nuwe lewe: "Die liefde moet opreg wees ... Betoon hartlike broederliefde teenoor mekaar" (vers 9 en 10). Die opdrag om liefde te betoon is hier gerig op mekaar, op die onderlinge verhoudings binne die gemeente. Die mekaar van vers 10 gaan in verse 17 en 18 oor in alle mense: "Wees goedgesind teenoor alle mense ... leef in vrede met alle mense." Die uitdrukking alle mense kan vir ons doeleindes beskou word as die tweede of wyer sirkel van liefdesbetoon. Die liefde vir mekaar en alle mense gaan in vers 20 oor in die derde of wydste sirkel van liefdesbetoon naamlik: "As jou vyand honger is, gee hom iets om te eet; as hy dors is, gee hom iets om te drink ...". Hierdie wydste opdrag is ingrypend van aard. As 'n vyand op sy swakste is (sonder kos en water) is die versoeking sterk om, juis in sy swakheid, op hom of haar wraak te neem. Die 
opdrag is egter: betoon liefde in konkrete dade. Hou jou vyand aan die lewe God wil nog met hom (en met jou?) werk.

Die radikaliteit van hierdie opdrag, hierdie onmoontlike moontlikheid deur die krag van die Gees, plaas 'n besondere klem op prediking oor politieke sake. Die strekking van hierdie opdrag hou in dat mense polities mag verskil, maar van vyandskap op politieke gronde mag daar nooit sprake wees nie - nie in die nouste sirkel van gelowiges nie en ook nie tussen mense in die gemeenskap nie. Dié opdrag relativeer inderdaad die politiek en bied 'n lens (die liefde) waardeur die politiek bekyk en waarin die politiek deur 'n gelowige beoordeel en beoefen behoort te word.

\section{Konklusie}

As resultaat van hierdie verkenning van Romeine 12 tot 15 word die volgende perspektiewe nou as stellings neergelê met die oog op prediking oor politieke sake.

- Prediking oor politieke sake (en verskille) moet as uitgangspunt en fundering hê die ontferming van God en nie menslike haat nie.

- Die feit dat die nuwe aeon alreeds maar nog nie finaal deurgebreek het nie, fundeer die stelling dat politiek - en prediking oor politieke sake - nog in die tyd van gebrokenheid plaasvind met die perspektief dat die finale deurbraak van die nuwe aeon voor hande is.

- Die wil van God ook vir die politiek en in die prediking oor politieke sake, moet biddend gesoek word omdat sy wil vir bepaalde sake nie altyd en oral reglynig dieselfde is nie.

- Die koninkryk van God relativeer alle politieke aardse koninkryke en die gawes van die koninkryk, byvoorbeeld geregtigheid vrede, vreugde, transendeer die gawes en die gebruik van gawes van aardse koninkryke.

- Die gawes wat God in sy kerk gee, het 'n taak tot toerusting van die gemeente om God se wil ook in politieke sake te onderskei. Hierby moet die prediker oor politieke sake in aanmerking neem dat hy bedienaar is in die gemeente en nie die gewete van die gemeente is nie.

- In sy verhouding tot God is die staat 'n dienskneg en in die verhouding tot onderdane 'n regeerder.

- Uitkringende liefdesbetoon - teenoor mekaar, alle mense en vyande - behoort 'n kardinale element te wees in prediking oor politieke sake. 


\section{Bibliografie}

ABINENO, J.L.C. 1972. The state according to Romans thirteen. South East Asia Journal of Theology, 14(1):23-27

BAUER, W. 1979. A Greek-English lexicon of the New Testament and other early Christian literature. Chicago : University Press.

COETZEE, J.C. 1995. Route map to the books of the New Testament Part 1. The letters of Paul. Orkney : EFJS.

COETZEE, J.C. 1996. Three essential elements of true preaching - indicative, imperative and by way of promise. Potchefstroom : Faculty of Theology.

DE GRUCHY, J. 1970. The church in our cities. Braamfontein : SACC.

VUYST, J. 1979. Recapitulatie en/of successie in Openbaring 4:1-9:10. (In De Vuyst, J., Floor, L., Versteeg, J.P. et al. Uw knecht komt. Amsterdam : Ton Bolland. p. 85-101.)

FLOOR, L. 1974. Indikatief en imperatief in die prediking. In die Skriflig, 7(29):7-20.

FLOOR, L. 1985. Koninkryk en politiek. (In Vorster, J.M. \& Van Wyk, J.H. Altyd reformeer. Gesprekke oor politiek en godsdiens. Braamfontein : De Jong. p. 94-99.)

GOLDSTEIN, R. 1973. Die politischen Paränesen in 1 Pt. 2 und Rom. 13:1-7. Bibel und leben, 14(2):88-104.

HELBERG, J.L. 1991. Die eis om geregtigheid by die profete. (In Helberg, J.L. red. Kerkwees as getuienis in Suid-Afrika vandag. Potchefstroom : Potchefstroomse Teologiese Publikasies. p. 1-15.)

HUTCHINSON, S. 1971. The political implications of Romans 13:1-7. Biblical Theology, 2l(3):49-59.

JOSUTTIS, M. 1980. Praxis des Evangeliums zwischen Politik und Religion. Munchen Kaiser.

KÄSEMANN, E 1980. Commentary on Romans. Grand Rapids : Eerdmans.

KRUGER, M.A. 1983. Openbaring, geloof en geregtigheid. 'n Eksegetiese ondersoek van Romeine 1-4 Pretoria : UP. (D.D.-proefskrif.)

LONG, T.G. 1989. The witness of preaching. Westminster : John Knox.

MULLLER, B.A. 1985. Die sosiopolitieke dimensie van koninkrykprediking. ( $I n$ Louw, D.J. red. Op die breuklyn. Kaapstad : NG Kerkuitgewers. p. 139-152.)

MÜLLER, B A. 1992. Hermeneutiek op die intervlak tussen eksegese en sosiale analise Praktiese Teologie in Suid-Afrika, 7:27-41.

NYGREN, A. 1978 Commentary on Romans. Philadelphia : Fortress.

OOSTERHOF, B.J 1987. Profeet en politieke prediking. (In Oosterhof, B J. red. Om de Schriften te openen. Kampen : Kok. p. 126-146.)

PIETERSE, H.J.C \& THERON, J.P.J. 1994. Die begeleiding van Afrikaanssprekende kerklidmate deur die prediking in 'n oorgangsproses. Praktiese Teologie in Suid-Afrika, 9:141-154.

PORTER, C.L. 1996. Romans and the reformation of community. Fincounter, 37(1):1-22. 
RIENECKER, F. 1980. A linguistic key to the Greek New Testament. Vol. 2. Grand Rapids : Zondervan.

SCHLIER, H.S. 1977. Der Römerbrief. Freiburg : Herder

SNYMAN, S.D. 1992. Politiek in die preek? 'n Illustrasie uit Amos. Nederduitse Gereformeerde Teologiese Tydskrif, 33(2):150-156.

VAN ROOY, H.F. 1991. Die Ou Testament en politieke samewerking met nie-Christene. (In Helberg, J.L. red. Kerkwees as getuienis in Suid-Afrika vandag. Potchefstroom : Potchefstroomse Teologiese Publikasies. p. 31-42.)

VAN WYK, J.H. 1985. Etiek en politiek. (In Van Wyk, J.H. \& Vorster, J.M. Altyd reformeer. Besinning oor politiek en godsdiens. Braamfontein : De Jong. p. 48-62.)

VAN WYK, J.H. 1991. Kerklike getuienis in 'n polities gepolariseerde Suid-Afrika. (In Helberg, J.L. red. Kerkwees as getuienis in Suid-Afrika vandag. Potchefstroom : Potchefstroomse Teologiese Publikasies. p. 172-192.)

VAN WYK, J.H. 1992. Predikant en politiek. In die Skriflig, 26(4):551-562.

VELEMA, W.H. 1972. Politieke prediking. Kampen : Kok.

VENTER, C.J.H. 1985. Die Pauliniese paranese in Romeine 12:1-15:13. 'n Eksegetiese studie. Potchefstroom : PUCHO. (Th.D.-proefskrif.)

VENTER, C.J.H. 1991. Versoening en die prediking van die versoening in Suid-Afrika vandag. (In Helberg, J.L. red. Kerkwees as getuienis in Suid-Afrika vandag. Potchefstroom : Potchefstroomse Teologiese Publikasies. p. 213-224.)

VENTER, C.J.H. 1996. Uitkringende liefdesbetoon. Kommunikatiewe handelinge in diens van die onderlinge liefdesgemeenskap in die kerk. Pretoria : RGN.

VORSTER, J.M. 1985. Kerk en politiek. Die roeping van die kerk in die Suid-Afrikaanse politieke problematiek. (In Van Wyk, J.H. \& Vorster, J.M. Altyd reformeer. Gesprekke oor politiek en godsdiens. Braamfontein : De Jong. p. 100-118.)

WILCKENS, U. 1982. Der Brief an die Romer. 3 Teilband Rom. 12-16. Neukirchener Benzinger. 